Carolina Costa Marcondes

\title{
O laudo pericial psicológico na ação de requalificação civil
}

Trabalho de Conclusão de Curso apresentado ao Programa de Pós-Graduação em Psicologia Jurídica da PUC-Rio como requisito parcial para obtenção do título de Especialista em Psicologia Jurídica.

Orientador: Eliana Olinda Alves

Rio de Janeiro

4 de agosto de 2016 
Todos os direitos reservados. É proibida a reprodução total ou parcial do trabalho sem autorização da universidade, da autora e do orientador.

\section{Carolina Costa Marcondes}

Psicóloga graduada pela PUC-Rio, pós-graduação em Psicanálise pelo CEPCOP da Universidade Santa Úrsula, faz parte da formação permanente da Escola de Psicanálise Letra Freudiana. Trabalha como psicanalista em clínica particular e é voluntária do Programa do TJ-RJ na Vara de Família. 
Dedico o trabalho aos colegas psicólogos que trabalham na Vara de Família. 


\section{Agradecimentos}

Agradeço as psicólogas Ana Alice Azevedo e Margaret Spohr por me haverem concedido espaço de trabalho, riquíssima experiência, na Vara de Família. 


\section{Resumo}

O presente estudo analisa a importância do conteúdo do laudo elaborado pelo psicólogo diante do pedido de requalificação civil feito à Justiça. O Sistema de Justiça, mais especificamente as Varas de Família, hoje, são responsáveis por julgar as ações de requalificação civil movidas por pessoas que se reconhecem como transgêneras. A ação de requalificação civil contém geralmente dois pedidos, mudança de nome próprio e redesignação de estado sexual. O processo é remetido à equipe interdisciplinar por determinação do juiz para estudo social e psicológico. $O$ psicólogo é então convocado a produzir o laudo psicológico. Acreditamos que este documento em seu caráter de produção de conhecimento/verdade ultrapassa o estudo pericial particular tendo a possibilidade de ampliar a reflexão sobre as identidades não previstas para os operadores jurídicos.

\section{Palavras-chave}

Pessoas transgêneras, laudo psicológico, requalificação civil, vara de família. 


\section{Sumário}

$\begin{array}{ll}\text { Introdução } & 8\end{array}$

$\begin{array}{lr}\text { Trans...formações trans } & 9\end{array}$

O que é direito para os "anormais"? 14

Possibilidades de inscrever-se $\quad 22$

$\begin{array}{ll}\text { Referências Bibliográficas } & 24\end{array}$ 
VERDADE

A porta da verdade estava aberta, mas só deixava passar meia pessoa de cada vez.

Assim não era possível atingir toda a verdade, porque a meia pessoa que entrava só trazia o perfil de meia verdade.

E sua segunda metade voltava igualmente com meio perfil. $E$ os dois meios perfis não coincidiam.

Arrebentaram a porta. Derrubaram a porta.

Chegaram a um lugar luminoso onde a verdade esplendia seus fogos.

Era dividida em duas metades, diferentes uma da outra.

Chegou-se a discutir qual a metade mais bela.

As duas eram totalmente belas.

Mas carecia optar. Cada um optou conforme seu capricho, sua ilusão, sua miopia.

Carlos Drummond de Andrade, $A$ verdade divina. 


\title{
Introdução
}

\author{
Eu queria querer-te amar o amor \\ Construir-nos dulcíssima prisão \\ Encontrar a mais justa adequação \\ Tudo métrica e rima e nunca dor \\ Mas a vida é real e é de viés \\ E vê só que cilada o amor me armou \\ Eu te quero (e não queres) como sou \\ Não te quero (e não queres) como és \\ (Caetano Veloso, O Quereres)
}

Trabalhando como psicanalista, interessei-me por estudar o que seria a diferença sexual para a psicanálise, questionamento que me levou até às chamadas dissidências sexuais. Nesse percurso de estudos e pesquisa, encontrei artigos escritos por estudiosos de diferentes áreas, bem como participei de espaços de produção e discussão, dentro e fora da área da psicologia e da psicanálise, envolvendo a temática das pessoas transgêneras. Ouvindo palestrantes, atenta aos debates dei-me conta de uma hostilidade dirigida ao lugar do psicólogo, visto por alguns como um agente normatizador que estaria a serviço das regulamentações médicas e jurídicas, em detrimento de uma escuta que privilegiasse o sujeito. Resumidamente, as críticas ao lugar do psicólogo diziam de uma falta de compromisso ético com o atendido, justamente por conta do compromisso com as demandas das instituições hospitalares e jurídicas.

Através do curso de Pós-Graduação em Psicologia Jurídica da PUC Rio, pude ocupar o lugar de psicóloga voluntária na equipe técnica de uma Vara de Família, tendo assim a oportunidade de receber a demanda do Juízo para a elaboração de um laudo para processo de requalificação civil. A partir das experiências vividas, pude questionar-me: qual o valor do laudo psicológico? E mais, qual o valor do laudo psicológico para o sujeito entrevistado? Este trabalho é o esforço de pensar a ética e questionar a prática, mas não sem antes introduzir o tema das transidentidades ou identidades transgêneras. 


\section{Trans...formações trans}

No Brasil, bem como em outros países, as questões que giram em torno das identidades dissidentes estão sendo amplamente discutidas por profissionais de diversos campos de saber, pela sociedade civil e pelas pessoas transgêneras. É importante frisar como as pessoas trans são ativas na produção de conhecimento sobre suas vivências, seja produzindo em ambientes acadêmicos ou fora destes.

As pessoas que se identificam como transgêneras saíram da invisibilidade e buscam um lugar não-marginal no grupo social. As identidades trans constituem um grupo amplo e diverso, havendo, apesar de uma suposta identificação maciça, divisões e discordâncias quanto ao entendimento sobre as possibilidades de identidades transexuais. Hoje, essas pessoas fazem laço em torno de uma busca em comum, o reconhecimento de suas identidades pelo campo jurídico, pleiteiam por novas inscrições, o que as tornariam menos frágeis socialmente através desse reconhecimento. Podemos dizer que é feito um pedido de reconhecimento ao Estado, com este reconhecimento jurídico, elas sairiam da marginalidade vivida hoje, na forma de inúmeras limitações em suas vidas cotidianas, muitas vezes alicerçadas no reconhecimento de suas identidades como patológicas.

A demanda de um reconhecimento não-marginal pelo grupo social passa pelo movimento de despatologização das identidades trans, que implica em maior autonomia dessas pessoas frente à tutela dos especialistas constituídos, hoje pelo Estado brasileiro. Tais especialistas analisam o caso daqueles que desejam passar pelo processo transexualizador de modificações corporais ou querem mudar de nome próprio e estado sexual'. Assim sendo são avalizados ou não tanto o processo transexualizador quanto o pedido de requalificação civil. Pensando sobre este tipo de prática, uma questão se apresenta: seriam os especialistas convocados a atestar sobre "o verdadeiro sexo" daquele que requer a mudança de identidade?

Chamamos aqui de "verdadeiro sexo", expressão cunhada por Foucault, ao suposto objeto de estudo e busca, empreendido pelos saberes jurídico, médico e psicológico, saberes que devem dizer sobre a verdade de um sexo

\footnotetext{
${ }^{1}$ A expressão estado sexual é utilizada, no poder judiciário, para processos de requalificação civil e diz respeito à identificação da pessoa como sendo do sexo feminino ou do sexo masculino.
} 
inequívoco, com base em parâmetros tidos como científicos. Saberes que tanto excluem como instituem, em um mesmo golpe, a equivocidade das identidades sexuais dissidentes. A equivocidade das identidades trans tende a ser desconstruída e até mesmo apagada, porque a identidade sexual deve ser una e inequívoca na sociedade ocidental moderna, como nos diz Foucault em seu livro "Herculine Barbin, dite Alexina B", diário de uma jovem hermafrodita, que abordaremos mais adiante.

Segundo o dicionário Houaiss da língua portuguesa, equívoco, em uma de suas acepções, é aquilo que pode ter mais de um sentido, mais de uma interpretação, aquilo que se pode tomar por outra coisa. O psicólogo que entrevista, deve criar um espaço potencial para acolher o dizer do sujeito entrevistado, o que será trabalhado mais adiante, deixando as verdades prontas de lado, esperando mais que "um" sentido.

A construção da verdade sobre o sexo está em jogo no atual processo de requalificação civil brasileiro, pois o sujeito não está autorizado a falar sobre sua verdade sem que a ciência, na figura do especialista, possa conferir ou não verdade ao saber do sujeito sobre si. Para uma mudança de identidade sexual no Brasil faz-se necessário tanto um diagnóstico médico, quanto protocolar um processo no judiciário, além de ser exigido também parecer-se com o gênero pleiteado o que pode incorrer na obrigatoriedade de mudanças corporais.

$\mathrm{Na}$ Argentina, a lei nacional 26743 de identidade de gênero, garante a toda pessoa o reconhecimento de sua identidade de gênero auto percebida, sem submetê-la a nenhum diagnóstico médico ou psicológico e também não judicializa o reconhecimento legal da própria identidade, habilitando a pessoa a proceder um trâmite administrativo para mudança de registro. No Brasil, a Lei João W. Nery, ainda não aprovada, propõe a dispensa da avaliação por especialistas, equiparando-nos ao tratamento argentino dado às pessoas transgêneras.

Ainda dentro do contexto brasileiro, analisando as sentenças decisórias sobre os pedidos de requalificação civil, disponíveis na internet, podemos cercar os parâmetros usados pelo Juízo para deferir ou não os pedidos de requalificação. As sentenças revelam, muitas vezes, uma busca pelo "verdadeiro sexo", ao fim do processo de requalificação será decidida a verdade sobre 0 sexo do requerente. Podemos dizer que empreender uma busca pelo "verdadeiro sexo" dentro do processo jurídico atual pode deixar o sujeito em sua verdade como variável menor, ou seja, tratar-se-ia de uma busca por um sexo sem sujeito. 
Tomamos aqui o conceito de sujeito segundo a psicanálise, sujeito como todo aquele que está às voltas com uma construção de verdade sobre si, construção que é também narrativa, com furos e falhas, próprios da constituição do eu, da linguagem e do corpo. Esta construção particular é atravessada, permeada pelas marcas/insígnias do social. O social é também um corpo, que dá vida, lugar, acolhe, e distribui possibilidades e impossibilidades para o sujeito. Podemos pensar nesse atravessamento contínuo entre sujeito e social com o Poema Sujo de Gullar (1976):

\author{
O homem está na cidade \\ Como uma coisa está em outra \\ E a cidade está no homem \\ Que está em outra cidade \\ Mas variados são os modos \\ Como uma coisa está em outra coisa \\ (...) Cada coisa está em outra \\ De sua própria maneira \\ E de maneira distinta \\ De como está em si mesma
}

As pessoas trans estão na cidade, como uma coisa está em outra e a cidade, como corpo social, está nas questões levantadas e apresentadas pelas identidades trans. O movimento de pensar as transformações nas identidades sexuais coloca em pauta as bases com que a comunidade (científica) sustenta a verdade sexual que constitui homens e mulheres. As identidades trans atestam e denunciam a insuficiência dos espaços possíveis criados para abrigar a verdade sobre o que é a diferença sexual como sustentada hoje pelas normas médicas e jurídicas, entre outras cerziduras.

A diferença sexual, em meio a protestos, cirurgias e pedidos de requalificação, clama por ser dita de outra maneira. Judith Butler, filósofa norteamericana, conhecida como uma das precursoras do Movimento Queer, em seu trabalho mais conhecido, "Problemas de Gênero" (2015), aborda a temática das dissidências sexuais, a partir da análise do filósofo francês, Michel Foucault. Butler trabalha as relações de poder e instituição de saberes, que produzem categorias de indivíduos, questionando as construções de identidades de gênero através do conceito de performatividade. O trabalho de Butler é amplamente usado pelos estudiosos e pelas militâncias como uma maneira de dialogar sobre 
as questões de gênero e mostrar os queers, que em inglês pode ser traduzido como os esquisitos, como um grupo que questiona as possibilidades do ser sexuado ou possibilidades de identificação sexuada. Butler, ao longo de sua produção, retoma os processos de humanização e desumanização dentro das sociedades modernas, em "Relatar a si mesmo" (2015), propõe a questão da filosofia moral como uma ferramenta de reflexão para o entendimento sobre as construções dos referenciais contemporâneos:

Gostaria de começar considerando como pode ser possível colocar a questão da filosofia moral - questão que tem a ver com conduta e, portanto, com o fazer dentro de um referencial social contemporâneo. Colocar a questão nesse quadro já é admitir uma tese a priori, a saber, não só que as questões morais surgem no contexto das relações sociais, mas também que a forma dessas questões muda de acordo com o contexto - e até o contexto, em certo sentido, é inerente à forma da questão. (BUTLER, 2015, p.13)

Podemos assim, a partir das análises de Butler, problematizar a construção daquilo que os especialistas denominam como patológico nas identificações sexuadas, bem como a delicada articulação dos elementos que na cultura produzem o patológico. A análise dos elementos normatizadores ou paradigmas reconduz, tanto a sociedade quanto a ciência a questionar o destino (i) moral a que essas identidades dissidentes foram relegadas.

Acompanhando historicamente a inclusão das identidades trans, em um primeiro momento, estas foram acolhidas pelo grupo social, através da ciência médica, como patologia psiquiátrica. É o momento de entrada nos compêndios de classificação de transtornos mentais e de comportamento, tais como o CID10. A transexualidade como patologia fica registrada no CID como F-64, transtornos de identidade sexual, agrupando três transtornos principais:

F 64.0 Transtorno de identidade sexual.

F 64.1 Travestismo de duplo papel.

F 64.2 Transtornos de identidade sexual na infância.

Dentro dessas três categorizações podemos determinar que pessoas estariam capturadas pelas diretrizes diagnósticas: aquelas que não se identificam à norma heteronormativa ou binária, sejam adultos ou crianças.

Nas sociedades que se utilizam do CID, devemos considerar que a entrada nos Compêndios retira as transidentidades da invisibilidade a partir do lugar da doença, que é um lugar previsto no corpo social. Este corpo social tem como 
obrigação acolher o sujeito doente e prestar cuidados; cuidados que devem recuperá-lo, para que possa regressar ao conjunto/espaço social. Ora, a pessoa trans não vai regressar ao corpo social, ele vai entrar no corpo social pela primeira vez, através da criação da doença que incorre na possibilidade do "tratamento", que culmina na identidade sexual não-equívoca, na heteronormatividade.

Contudo, a compreensão da transexualidade é, hoje, ampliada através da entrada dos mais diversos campos de saber; antropólogos, sociólogos, psicólogos e pessoas trans enriquecem o campo do pensar para além das normas vigentes. Ainda que a criação de um lugar nos compêndios de transtorno mental tenha sido o primeiro espaço habitável, previsto para o reconhecimento das identidades trans pelo grupo social, hoje uma grande parte dessas pessoas faz apelo a um reconhecimento que ultrapasse a visão de suas identidades como patológicas.

Consideremos a ligação entre despatologização e autonomia jurídica, no Brasil, o entendimento das pessoas trans como inscritas dentro de uma patologia psiquiátrica é usado como parâmetro nas decisões judiciais. O reconhecimento das diretrizes diagnósticas do CID F-64 é hoje, na maioria dos casos, necessário para que essas pessoas consigam mudar de nome próprio e de estado sexual no Sistema de Justiça. O mesmo ocorre com o sistema público de saúde, onde esse diagnóstico é necessário para que essas pessoas possam ter acesso à cirurgia de transgenitalização e tratamentos outros, associados. O psicólogo, no judiciário, fica no difícil lugar de produzir um documento que terá que ponderar entre a construção de identidade do sujeito pelo sujeito e aquilo que conhece como sendo a norma médica que influi na tomada de decisão dos magistrados.

Trataremos aqui de um momento específico da jornada dessa pessoa que demanda ao judiciário a alteração de seu nome próprio e estado sexual. Melhor dizendo, demanda ao Estado reconhecer seu nome próprio e sua identidade sexual. Pensemos no documento elaborado pelo psicólogo diante deste pedido de reconhecimento de uma identidade não prevista juridicamente, tratando da produção de verdade possível nesse encontro. 


\section{O que é direito para os "anormais"?}

Foucault, à época do seu escrito "A História da Sexualidade", encontrou na Biblioteca Nacional da França, "A História de Alexina B", manuscrito de uma jovem hermafrodita, diário publicado pela primeira vez, em 1874, pelo médico Ambroise Tardieu, que após a primeira publicação foi perdido. Tardieu omitiu a parte final do diário de Herculine Barbin, cujo nome fora alterado para publicação.

A segunda edição do diário de Herculine é publicada, na França, dentro da obra "Questão médico-legal de identidade: lembranças e impressões de um indivíduo cujo sexo era desconhecido". A palavra que Tardieu usa em francês para "desconhecido", no título, é méconnue, que pode significar aquilo que não foi apreciado no seu devido valor, tradução que nos parece mais interessante que desconhecido ao considerarmos a problemática da apreciação sobre o reconhecimento de identidades "anormais" ou fora da norma.

Ao retomar o diário, em 1980, Foucault escreve o prefácio fazendo um apanhado histórico sobre o século XVIII, onde as teorias biológicas da sexualidade, as condições jurídicas do indivíduo e as formas de controle administrativo conduziram, aos poucos, à recusa daquilo que ele denominou "uma mistura de dois sexos em um só corpo". Dessa forma, restringiram, para o autor, a livre escolha dos "indivíduos incertos", outra expressão criada para referir-se àqueles que não eram enquadráveis nos padrões de identidade sexual: "A partir de agora para cada um, um sexo e somente um", imperativo que estabelece os limites para as identificações possíveis. A medicina passa a ter o papel de decifrar o "verdadeiro sexo" que "se esconde sob aparências confusas", ao médico cabe encontrar o único, verdadeiro sexo:

Do ponto de vista do Direito, isso implica evidentemente no desaparecimento da livre escolha. Não cabe mais ao indivíduo decidir a qual sexo ele quer ser, juridicamente ou socialmente; mas cabe ao expert dizer qual o sexo que a natureza escolheu para este, e ao qual, consequentemente, a sociedade irá demandar que nele se sustente. A justiça, se fizermos apelo a esta (logo que, por exemplo, desconfia-se que alguém não vive sob seu verdadeiro sexo e 
casou-se abusivamente) terá que restabelecer a legitimidade de uma natureza que não foi suficientemente bem reconhecida. ${ }^{2}$ (FOUCAULT, 2014, p.12)

Nossa intenção é resgatar a atualidade da discussão que Foucault levanta, analisando desde o lugar do expert a ideia do verdadeiro sexo. O Diário de Herculine Barbin, relato autobiográfico de uma mulher nascida em 1838 que, em 1860, pelo julgamento de um Tribunal Civil na França, foi ordenada a retificação de seu nome próprio e estado sexual, é um ponto de referência para pensarmos os desdobramentos dos atuais processos jurídicos em torno da identificação sexuada em seus efeitos no laço social.

O diário de Herculine, o que nos revela? Sua letra nos diz de suas vivências, sentimentos, questionamentos. A beleza do depoimento está na clareza (e angústia) com que escreve seus anos, da infância à vida adulta, seus relacionamentos, sua entrada na vida social para além dos muros das instituições religiosas onde viveu. O diário alcança o momento do encontro entre Herculine adulta e os ordenadores dos hábitos, igreja, medicina e Estado, nesta ordem. Herculine busca o padre da vila, insiste em ser escutada, e a igreja a encaminha aos médicos. Os representantes do saber divino entendem que o saber divino não pode versar sobre a verdade de Herculine.

Os médicos são então chamados, não para ouvir Herculine, mas para examinar seu corpo. O corpo deveria em si atestar a verdade, e aí podemos nos perguntar sobre a construção de verdade do especialista da ciência que fez de Herculine, Abel. Temos assim a aparição do corpo sem sujeito. O corpo examinado apesar da fala do sujeito que o habita.

Quão longe estamos de 1860 no que diz respeito à busca pelo verdadeiro sexo atestado pelo especialista?

Cento e vinte anos depois da retificação feita pelos especialistas, onde Herculine desaparece para que Abel possa constar nos registros franceses, Foucault intitula seu prefácio, em 1978, de "O verdadeiro sexo". Trinta e seis anos depois de Foucault, em 2014, Eric Fassin intitula seu posfácio de "O verdadeiro gênero", fazendo menção, entre outras coisas, a criação e absorção da categoria de gênero que movimenta e desmembra a compreensão sobre a identidade que habita o corpo.

\footnotetext{
${ }^{2}$ Tradução livre da autora.
} 
A expressão "indivíduos incertos", cunhada por Foucault, fez-nos pensar aqui, não nas pessoas trans, mas no especialista, este outro examinador que pode fazer passar, ou não, uma certeza do indivíduo às incertezas públicas, através da escrita de laudos e verdades outras. Herculine teve seu nome e seu estado sexual modificados pelos agentes da verdade, sendo sua certidão de nascimento retificada:

Por julgamento do tribunal civil de Saint Jean d'Angély na data de 21 junho de 1860, foi ordenado o ato aqui escrito fosse retificado nesse sentido: 1) que a criança aqui colocada será designada como pertencendo ao sexo masculino; 2) e que o nome de Abel substituirá aquele de Adelaide Herculine. Saint Jean d’Angély, 22 de junho de 1860 . (FOUCAULT,2014,p.171.)

\title{
O laudo psicológico como produção de verdade (s)
}

\author{
A porta da verdade estava aberta, \\ Mas só deixava passar meia pessoa de cada vez. \\ Assim não era possível atingir toda a verdade, \\ Porque a meia pessoa que entrava \\ Só trazia o perfil de meia verdade. \\ E sua segunda metade \\ Voltava igualmente com o meio perfil. \\ $E$ os meios perfis não coincidiam. \\ (DRUMMOND, 1981, p. 41)
}

A perícia psicológica é um recurso previsto no Código de Processo Civil e suas diretrizes estão colocadas na Resolução do Conselho Federal de Psicologia, CFP 008/2010, para instruir litígios processuais no judiciário, tanto nas Varas de Infância quanto nas Varas de Família. O laudo, como uma prova técnica, é uma ferramenta para auxiliar o juiz em suas decisões, dentro de um campo de saber específico, entendido como necessário e complementar à prática jurídica.

As Varas de Família têm a competência de julgar as ações de requalificação civil que contêm geralmente dois pedidos: mudança de nome 
próprio e mudança de estado sexual, podendo haver deliberação do juízo para autorizar a mudança de nome e negar a mudança de estado sexual. Hoje, no Brasil, o laudo pericial psicológico é um estudo que faz parte do processo. O que se faz necessário constar neste laudo?

Shine (2009), coloca que o laudo é o produto consubstancializado daquilo que foi feito na interação direta com as pessoas atendidas, proposta de trabalho que nos convoca ao inédito do encontro com cada pessoa em seu processo. Neste encontro com o inédito, segundo o autor, o psicólogo, na função de avaliar para conhecer, traduz a verdade do sujeito e ao mesmo tempo a fabrica:

Como se vê a "busca da verdade" justifica o recurso à prova pericial, uma vez que a própria decisão judicial pretende "fundamentar-se cientificamente" nela, evitando "obscuridades, opiniões pessoais ou ambiguidade". Parece-nos que se postula uma decisão judicial impessoal e asséptica, erigindo o ideal de ciência neutra e objetiva como parâmetro norteador do procedimento jurídico. (SHINE, 2009, p.29)

Nossa hipótese é que essa escrita, o laudo, tem o alcance de produzir uma verdade, que acaba por ser endereçada não somente aos operadores jurídicos e ao requerente, mas a outros campos de saber, sejam científicos ou não, repercutindo, possibilitando pensarmos as existências juridicamente inéditas habitando espaços potencialmente comuns. As verdades de valor documental/científico são produzidas por agentes de saber, no caso das ações de requalificação civil podemos nomear alguns deles: assistentes sociais, magistrados, médicos e psicólogos. Cada um deles fica responsável por representar um campo de saber e exercer "poder", de conferir razão científica ou não ao pedido de requalificação.

Esse conjunto de documentos anexados ao processo deve, ao final constituir uma verdade. Mas seria possível juntar os pedaços da pedra e formar um sýmbolon ou estaria o sistema de Justiça deliberando a verdade através da prova do ordálio?

Foucault (2013) coloca-nos que na antiga Grécia havia um procedimento de testemunho baseado na escolha daquele que poderia atestar/reconhecer a verdade sobre determinado assunto ou fato. Para essa pessoa era dado o pedaço de um objeto, que fora partido, podendo ser uma pedra; apenas aqueles que portassem os pedaços que fizessem encaixe poderiam testemunhar sobre a verdade, este objeto quebrado a ser encaixado posteriormente é nomeado sýmbolon: 
Ela consiste na famosa técnica do sýmbolon, o símbolo grego. Um instrumento de poder, de exercício de poder que permite a alguém que detém um segredo ou um poder quebrar em duas partes um objeto qualquer, de cerâmica, etc., guardar uma das partes e confiar a outra parte a alguém que deve levar a mensagem ou atestar sua autenticidade. É pelo ajustamento destas duas metades que se poderá conhecer a autenticidade da mensagem, isto é, a continuidade do poder que se exerce. O poder se manifesta, completa seu ciclo, mantém sua unidade graças a este jogo de pequenos fragmentos, separados uns dos outros, de um mesmo conjunto, de um único objeto, cuja configuração geral é a forma manifesta de poder. (FOUCAULT, 2013, p.45)

Entre alguns dos povos europeus, quando para deliberarem sobre um conflito, as partes discordantes seriam submetidas a procedimentos probatórios, tais como uma demonstração de força física, o corpo entre em cena. Esses procedimentos eram as provas dos ordálios. A verdade era consequência de uma disputa de força ou resistência:

Havia, finalmente, as famosas provas corporais, físicas, chamadas ordálios, que consistiam em submeter uma pessoa a uma espécie de jogo, de luta com seu próprio corpo, para constatar se venceria ou fracassaria. (...) no fundo, trata-se sempre de uma batalha, trata-se sempre de saber quem é o mais forte. No velho Direito Germânico, o processo é apenas a continuação regulamentada, ritualizada da guerra. (FOUCAULT,2013, p.63)

Ferrasin (2011), diz que os ordálios eram procedimentos que lidavam com situações em que o conhecimento era impossível, mas a incerteza intolerável. Pensemos nos dois pontos dessa frase: conhecimento impossível e incerteza intolerável. Seria o papel do perito responsabilizar-se pelo intolerável da incerteza sobre o outro?

O que o psicólogo sabe antes do encontro com o sujeito que requer a requalificação civil? Faz-se importante lembrar que nos autos do pedido de requalificação todos falam sobre o requerente, menos o próprio requerente. $\mathrm{O}$ requerente é falado. Entre o requerente do processo e o sujeito da fala está o espaço da entrevista com o psicólogo.

Assim sendo, a ação de requalificação civil fez-nos pensar nas lógicas do sýmbolon e do ordálio. Há diferentes discursos e agentes de discurso que atestam a suposta verdade sobre o sexo do sujeito na peça processual, 
verdades que podem ser coincidentes ou não. Esses agentes, detentores dos diferentes pedaços da pedra, têm importâncias diferentes na cena jurídica. Nos processos de requalificação civil, entre os documentos anexados à ação judicial, encontramos laudos confeccionados pelos especialistas: médicos (cirurgiões, endocrinologistas), assistentes sociais e psicólogos. Os documentos dos especialistas são diferentes pedaços do objeto partível, que supostamente deveriam encaixar e atestar a verdade una, inequívoca e final. Como analogia à prova do ordálio, podemos pensar nos corpos trans exigidos como prova documental, através da análise de fotos ou exigências cirúrgicas. Para muitos magistrados é necessário parecer-se com um corpo masculino ou feminino, o corpo faz prova e é exigido como prova.

Freire (2015) problematiza a produção de verdade nos pedidos judiciais de requalificação civil:

(...) distintos documentos são capazes de produzir, dar materialidade e estabilizar a realidade sobre o sexo e gênero de pessoas transexuais ao classificar indivíduos em determinadas categorias, atestar alguns aspectos da vida dos sujeitos, comprovar certas experiências e construir narrativas e trajetórias concisas. Além disso, a produção de verdade sobre o sexo e o gênero se dá em meio a disputas e apropriações de teorias formuladas em diversos campos de saber, que são fundamentais para o acesso ao direito de alteração de nome e/ou sexo no registro civil. (FREIRE, 2015, p.89)

Importante destacar quais os espaços ocupados pelo psicólogo, enquanto profissional que faz parte de instituições que atendem à população trans: equipe multidisciplinar do Sistema Único de Saúde; Defensoria Pública e Vara de Família. Como parte da equipe técnica da Vara de Família, o psicólogo produzirá um laudo, documento que respeitará os procedimentos próprios da perícia judicial, bem como as diretrizes e especificações do Conselho Federal de Psicologia. Tais diretrizes versam não só sobre a redação e objetivos do documento, mas sobre as especificações para atendimento às pessoas transexuais. Podemos dizer que nos lugares referidos acima, o psicólogo atuará na produção de documentos diferentes, posto que corresponderão às especificidades das demandas das instituições em que trabalham.

O laudo elaborado pelo psicólogo do SUS, profissional da equipe multidisciplinar preparada para receber o usuário do programa de apoio ao processo transexualizador, estará voltado para o acompanhamento do paciente 
e seu trabalho/estudo/laudo deve estar de acordo com as políticas do serviço médico, em sua organização e concepção para este atendimento. O documento elaborado pela Defensoria Pública faz parte da ação de requalificação civil de maneira a promovê-la. A entrevista com o psicólogo da Vara de Família é a última de uma série de entrevistas no percurso do sujeito. O psicólogo da Vara de Família ao receber o processo vai deparar-se com os seguintes documentos:

a) peça do defensor público ou de advogado constituído pelo requerente;

b) relatório do assistente social da defensoria pública, no caso de uma ação haver sido proposta pela Defensoria;

c) relatório do assistente social da equipe interdisciplinar da Vara de Família;

c) relatório do psicólogo da defensoria pública;

d) certidões emitidas pelos Ofícios de Registro de Distribuição (ORD), que são nove na cidade do Rio de Janeiro.

e) laudos médicos quando o paciente já passou por alguma cirurgia ou passa por algum tipo de tratamento, podendo ser de médicos particulares ou de instituições públicas, com detalhamento dos procedimentos realizados;

f) cartas de diferentes pessoas que convivam com o requerente e que atestem sua identidade de gênero como permanente há mais de dois anos, tais como: empregadas domésticas, professores, amigos, colegas de trabalho.

g) fotos: com amigos, em eventos familiares, de corpo inteiro, que atestem um tipo físico e papel social correspondente ao estado sexual requerido;

h) documentos do Ministério Público.

Nas petições dos advogados ou defensores, que costumam ser extensas, encontramos uma série de referências à Constituição da República Federativa do Brasil, especialmente aos artigos que dizem da promoção e proteção dos direitos fundamentais; Resoluções do Conselho Federal de Medicina; tratados internacionais, especialmente os Princípios de Yogyakarta; portarias do Ministério da Saúde e algumas citações de sentenças positivas proferidas por juízes em outros casos de requalificação civil.

O princípio da dignidade humana e o direito à personalidade, direitos fundamentais garantidos pela Constituição do Brasil, são os conceitos norteadores das peças dos advogados, podemos encontrar nos documentos feitos pelos psicólogos e assistentes sociais, ênfase em apontamentos sobre a violação de tais direitos. Em todos os documentos anexados à ação dá-se 
ênfase à violência e à marginalização geradas pela inconformidade entre a identidade de gênero, nome próprio e estado sexual. Discorre-se assim sobre a importância em poder franquear o espaço público. O pedido endereçado ao Estado é um pedido de reconhecimento, direito de ser e estar. Ser e estar também nesse pequeno-grande espaço das cédulas de identidade que dizem do nome-próprio e do sexo. Mas qual a importância de todo o conteúdo do processo para o laudo do psicólogo da Vara de Família?

O psicólogo da Vara de Família deve levar em conta, em seu estudo, os documentos que constam no processo, isso quer dizer que todos os documentos anexados são também objetos de análise. Nas Referências Técnicas para atuação do psicólogo em Varas de Família, manual elaborado pelo CFP, faz-se uma demarcação do campo de atuação profissional do psicólogo nas referidas Varas, onde as práticas são próprias da área de Psicologia Jurídica. Como o próprio nome indica há um encontro entre a Psicologia e o Direito, com princípios particulares que orientam esse encontro.

As Recomendações do CFP, muito oportunamente, lembram-nos que o psicólogo precisa considerar quais os efeitos de seu trabalho para além de cada caso atendido. O estudo, como documento, contribui para a consolidação de representações e práticas sociais, logo os pedidos de requalificação civil dificilmente podem ser entendidos unicamente como situações particulares a serem julgadas em seus pleitos.

Hoje, pensar as questões de identidade e sexualidade dentro de uma perspectiva de transdisciplinaridade enriquece o que é produzido no encontro entre sujeito e Estado. Dalsenter, em seu artigo "Do corpo natural ao corpo transformado" pondera a necessidade do campo jurídico dialogar com diferentes atores sociais e bases interdisciplinares:

À luz da ciência jurídica, os estudos sobre a transexualidade insistem em desenraizar o fenômeno, tratando apenas de suas consequências na medida em que estas interessam diretamente ao Direito. Entretanto, compreender os fatos juridicamente é tarefa que deve estar alicerçada sempre em bases transdisciplinares, para que seja possível ver além dos limites impostos pelos dogmas jurídicos. Isto é, torna-se imperiosa a tarefa de desvendá-los como desdobramento jurídico daquilo que se consolida historicamente no plano social e político: o paradigma. Um paradigma é um conjunto de perspectivas dominantes em torno da concepção do ser, do conhecer e do homem que, em períodos de estabilidade paradigmática, adquirem uma autoridade tal que se naturalizam. (DALSENTER, 2013, p.262) 


\title{
Possibilidades de inscrever-se
}

\author{
Meu corpo não é meu corpo, \\ E ilusão de outro ser. \\ Sabe a arte de esconder-me \\ E é de tal modo sagaz \\ Que a mim de mim ele oculta. \\ Meu corpo, não meu agente, \\ Meu envelope selado, \\ Meu revólver de assustar, \\ Tornou-se meu carcereiro, \\ Me sabe mais que me sei. \\ (DRUMMOND, 1981, p.41.)
}

As pessoas trans promovem uma desarrumação nos grandes saberes sabidos, extrapolando as duas possibilidades possíveis da cédula de identidade, homem ou mulher. Esta desarrumação causa efeitos: o que é tão ameaçador quando sustentamos nossas identificações e seus efeitos em nossos corpos?

O corpo particular, restrito, único, movimenta o corpo social. O laudo em seu dever de atestar a verdade deverá apontar para a importância de ouvir o sujeito e elevar sua fala à dignidade de produção válida. A discussão sobre autonomia e norma encontra na questão trans uma visibilidade inevitável: "Quem sois? "A cada entrevista na Vara tem-se o "ato de dizer-se", uma sustentação.

Ao falar do laudo elaborado pelo psicólogo da Vara de Família consideramos que estamos sujeitos à ética do Direito que regula o desejo individual no laço social. A lei regulamenta aquilo que o sujeito pode desejar para si. Aliás, o que seria regular o bem para o sujeito? O psicólogo deve estar advertido sobre o conflito entre o que se constitui como o bem para o campo jurídico e o que se constitui como benefício para o sujeito. A esse respeito, Ventura e Schramm (2009) fazem uma análise sobre os obstáculos que se interpõem ao sistema de garantia de direitos, que sustentam o laço social. Entre os ditames da lei e o dito do sujeito algo deve ser escrito.

Em Roma, há para os turistas a grande roda de pedra conhecida como La Bocca della Veritá. Diz-se que as pessoas que falavam coisas que eram postas sob suspeita iam para a frente da grande boca de pedra e aí depositavam sua mão. Caso aquilo que atestavam não fosse uma verdade a grande boca de pedra se fecharia e o sujeito perderia a mão.

Tomamos essa imagem para pensar a função do psicólogo diante do pedido de requalificação civil. O psicólogo ao não acolher o que é a verdade para determinado sujeito, fecha a boca, mutila. Mutilação que abarca o corpo, se 
o psicólogo, como a grande boca de pedra não se fecha, acolhe a verdade que o sujeito deposita em seu corpo.

Pensemos no Código de Ética do psicólogo, onde nos parágrafos que norteiam os princípios fundamentais da profissão, encontramos como diretrizes, a promoção da dignidade e a importância da análise crítica em suas vertentes histórica, política e cultural. Esses princípios fazem uma costura entre o meio e o tempo. Portanto, no momento da entrevista na Vara de Família, o psicólogo trata do meio familiar e social, do tempo particular e histórico das identificações para o sujeito.

Ao lidar com a experiência do encontro com esse sujeito, pensamos que não há possibilidade de um saber prévio ao encontro, não há perito antes do dizer do sujeito. Nessa perspectiva, assinalamos uma relação ética com o sujeito que possibilita a sustentação, no laço social, representado pelo judiciário, de corpos e identidades não previstos. 


\section{Referências Bibliográficas}

ANDRADE, Carlos Drummond de. Corpo. Rio de Janeiro: Editora Record, 1984. BUTLER, Judith. Problemas de Gênero. Feminismo e subversão da identidade. Rio de Janeiro: Editora Civilização Brasileira, 2015.

Relatar a si mesmo. Crítica da violência Ética. Belo Horizonte: Editora Autêntica, 2015.

BRASIL. Constituição da República Federativa do Brasil, de 05 de outubro de 1988. Disponível em <www.planalto.gov.br/wp-content/uploads/2013/09/Notatécnica-processo-Trans.pdf>. Último acesso em 26 de julho de 2016.

BRASIL. Projeto de Lei 5002/2013. Lei João W. Nery. Lei de Identidade de Gênero. Disponível em: <www.camara.gov.br/proposicoesweb/prop_ mostraintegra?codteor $=1059446 \&$ filename $=p l+5002 / 2013>$. Último acesso em: 26 de julho de 2016.

CONSELHO FEDERAL DE PSICOLOGIA. Nota técnica sobre processo transexualizador e demais formas de assistência às pessoas trans. Disponível em: <site.cfp.org.br>. Último acesso em 28 de junho de 2016

Referências técnicas para atuação do psicólogo em Varas de Família. Disponível em:<www.crecop.pol.org.br>. Último acesso em 24 de junho de 2016. Resolução no 007/2003. Institui o Manual de Elaboração de Documentos Escritos produzidos pelo psicólogo, decorrentes de avaliação psicológica. Disponível em: <site.cfp.org.br/wp-content/uploads/2003/06/resolucao2003_7.pdf >. Último acesso em 26 de julho de 2016.

. Resolução n008/2010. Dispõe sobre a atuação do psicólogo como perito e assistente técnico no Poder Judiciário. Disponível em: <site.cfp.org.br/wpcontent/uploads/2010/07/resolucao2010_008.pdf>. Último acesso em 26 de julho de 2016.

DALSENTER, Thamis Ávila. Do corpo natural ao corpo transformado: um panorama jurídico do transexualismo, 2013. Disponível em:

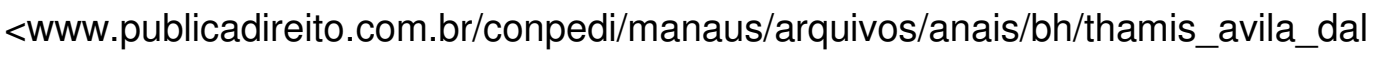
senter.pdf>. Último acesso em 26 de julho de 2016.

FERRASIN, Marcelo Moreira. Ordálios, historiografia e os escritos episcopais de Agobardo e Hincmar. Disponível em: <www.snh2011.anpuh.org/resources/ 
anais/14/1308183915_ARQUIVO_Artigoordalios-ANPUH.pdf.>. Último acesso em: 26 de julho de 2016.

FOUCAULT, Michel. A verdade e as formas jurídicas. Rio de Janeiro: Nau Editora, 2013.

Herculine Barbin dite Alexina B. Paris: Gallimard, 2014.

FREIRE, Lucas. Certificações de sexo e gênero: a produção de verdade nos pedidos judiciais de requalificação civil de pessoas transexuais. Disponível em: $<$ www.uel.br/revistas/uel/index.php/mediacoes/article/view/20970>.Último acesso em: 26 de julho de 2016.

GULLAR, Ferreira. Poema Sujo. Disponível em: <www.static. recantodasletras.com.br>. Último acesso em 24 de junho de 2016.

ORGANIZAÇÃO DAS NAÇÕES UNIDAS. Classificação de Transtornos Mentais e de Comportamento da CID-10. Descrições clínicas e diretrizes diagnósticas. Porto Alegre: Artes Médicas, 1993.

Princípios de Yogyakarta. Disponível em: <www.yogyakartaprinciples. org >. Último acesso em: 26 de junho de 2016.

ARGENTINA. Lei Nacional 26743 de Identidad de Genero. Disponível em: $<$ www.ms.gba.gov.ar/sitios/tocoginecologia/files/2014/01/ley-26743-identidad-degenero.pdf>. Último acesso em 28 de junho de 2016.

SHINE, Sidney K. Andando no fio da Navalha: riscos e armadilhas na confecção de laudos psicológicos para a justiça. 256f. Tese (Doutorado) - Programa de Pós-Graduação em Psicologia, USP, 2009. Disponível em:< www.teses.usp.br/teses/disponiveis/47/47131/tde-25022010-100314>. Último acesso em 24 de junho de 2016.

VELOSO, Caetano. O Quereres. Disponível em: <www.letras.com.br>. Último acesso em 22 de junho de 2016.

VENTURA, Mirian; SCHRAMM, Fermin R. Limites e possibilidades do exercício da autonomia nas práticas terapêuticas da modificação corporal e alteração da identidade sexual. Disponível em <http://dx.doi.org/10.1590/SO10373312009000100005>. Último acesso em 22 de junho de 2016. 